Differentiated Instruction in Teaching and Teacher Education: the DI-Quest model.

Peer-reviewed author version

STRUYVEN, Katrien; Gheyssens, Esther \& Griful-Freixenet, Julia (2019)

Differentiated Instruction in Teaching and Teacher Education: the DI-Quest model.. In: Peters, Michael A. (Ed.) Encyclopedia of Teacher Education, Springer,.

DOI: 10.1007/978-981-13-1179-6_48-1

Handle: http://hdl.handle.net/1942/28146 


\title{
Differentiated Instruction in Teaching and Teacher Education: the DI-Quest model
}

\author{
Katrien Struyven ${ }^{1,2}$, Esther Gheyssens ${ }^{2}$ and Júlia Griful-Freixenet ${ }^{2}$ \\ ${ }^{1}$ Hasselt University - School for Educational Studies, ${ }^{2}$ Vrije Universiteit Brussel - Educational \\ Science Department
}

Differentiated instruction is an educational concept that is highly valued and promoted by educators all over the world. In its most general meaning, differentiated instruction is the set of all interventions available to the teacher to respond to academic differences between learners. This refers to differences in student features which may impact learning, such as gender, age, developmental stage, interest, motivation, intellectual ability, learning preferences, pace of learning, socio-economic status, background and family situation. This heterogeneity in students is obvious in nearly every classroom, plausibly worldwide. Although the biological and psychological processes might appear to be similar among learners, a wide range of contextual factors make learning into a unique experience for every learner.

With differentiating instruction, it is assumed that diverse students might 'need' (or read: benefit from) different learning pathways to be successful in attaining the learning objectives. These learning pathways can be constructed within each classroom by every teacher. Differentiated instruction is about finding the right 'strings to get the puppets dancing'.

'It is about knowing where students are, and then aiming to move them ' +1 ' beyond this point. Teaching of the 'whole class' is unlikely to pitch the lesson correctly for all students. This is where the skill of teachers in knowing the similarities across students and allowing for the differences becomes so important. Differentiation relates primarily to structuring classes so that all students are working 'at or $+\mathbf{1}$ ' from where they start, such that all can have maximal opportunities to attain the success criteria of the lesson' (Hattie, 2012, p.97).

This 'at or +1 ' notion of Hattie (2012), reminding us about Vygotsky's socio-constructivist theory of the Zone of Proximal Development, is related to three key academic differences in differentiated instruction, namely: student interests, readiness and learning profile. Intriguingly, most relevant student features for academic success show themselves through these three differences. Hence, this chapter introduces readers to the three academic differences that are key to Differentiated Instruction (DI). Describing teachers' philosophy and practices of differentiated instruction, the empirically validated DI-Quest Model is presented next. Thirdly, the chapter highlights some implications for the implementation of DI in teaching and teacher education.

\section{Differentiated instruction: knowing where to start from...}

Teachers' responsiveness to these three differences in learning is essential in differentiated instruction frameworks, such as the well-known work of Tomlinson (2017). Student interests, 
readiness and learning profile relate to the why, the what and the how of learning. As such, the potential of differentiated instruction could be found in increased motivation (why of learning), learning gains for more students (what of learning) and heightened learning efficiency (how of learning).

The 'why' of learning - differences in interests

Individuals differ in the degree to which they are interested in certain subjects, topics or items. Responding to students' interests motivates positive learning behavior such as the willingness to take up a challenge and the persistence or the extent to which students maintain their commitment (Tomlinson, 2017). Whenever a person learns about 'why something might be interesting, relevant or meaningful', their curiosity to discover more is triggered. Therefore, understanding what intrigues students and responding to these differences during their learning process may help to develop students' motivation. Questions from learners such as 'Why should we learn this? Why is this relevant? When will we need this? What's the point?' could be considered as clues from students that the 'why of learning' is not being answered meaningfully. Adapting to Hattie's (2012) 'where they are at or +1 ' level relates to finding connections with students' interests with real-life events or with future jobs. Both existing interests, as well as the discovery of new interests, will trigger the willingness and curiosity to learn more. The teacher can do this, for example, by offering choices to students or making student-centered choices in terms of content, process and products of learning.

The 'what' of learning - differences in readiness

The differences in readiness are expressed on (meta-) cognitive, (social-) affective and (psycho-) motoric levels. In fact, 'what students learn' is connected to their prior knowledge and skills within the disciplines, areas, topics and items that are covered. Differences in readiness generate differences in student experiences, with some students finding it (too) difficult, whereas others think it is (too) easy. Both groups of students might 'give up' paying attention and risk not learning at all. Adapting teaching to take into account these differences in readiness will guarantee that learners can learn at the present and the desired ' +1 ' level. Teachers may want to play with the difficulty- and complexity-levels of the content, activities, learning materials or assignments. Moreover, scaffolds, learning aids and feedback are useful tools to help students to bridge the gap between where they start and the +1 level.

The 'how' of learning - differences in learning profile

In addition to differences in interest and readiness, students differ also in their learning profiles, or, in short, the way in which they learn - the how of learning. For example, some learners like to cooperate, others enjoy working independently; some need silence to focus on their work, whereas others turn on music while studying; some students start reading a text carefully from $A$ to $Z$, others skim through and get on with answering questions right away. Obviously, this can vary between different subjects and topics and across diverse contexts. 
The teacher can consider these differences by means of (1) providing options, (2) offering varying assignments, sources and materials and (3) dealing flexibly with the resources that are available. If students are given options, they will select those that 'work best' for them at that moment. For example, 'you can choose to work in pairs or individually'. Consequently, taking learning profiles into consideration will increase the efficiency level of learning. In addition, a varied learning/teaching environment which provides 'tastes' of every option (e.g. social skills are important, that is why we opted to combine cooperative assignments with independent work) is more appealing to diverse learning profiles in comparison to one-size-fits-all choices. A third way to deal with diverse learning profiles is to create flexible environments (e.g. Do you want to work in a quiet space? Do you need headphones to cancel noise? Do you need more time? Do you want to check the internet? Sure, go ahead.).

Three kinds of learning gains

Adaptive teachers who take into account students' learning needs for each of these academic differences in their teaching have a positive impact on students' learning gains. It is the combination of finding meaningful answers for each student to the 'why, what and how questions of learning', resulting in higher motivation, better learning and with heightened efficiency (see Figure 1).

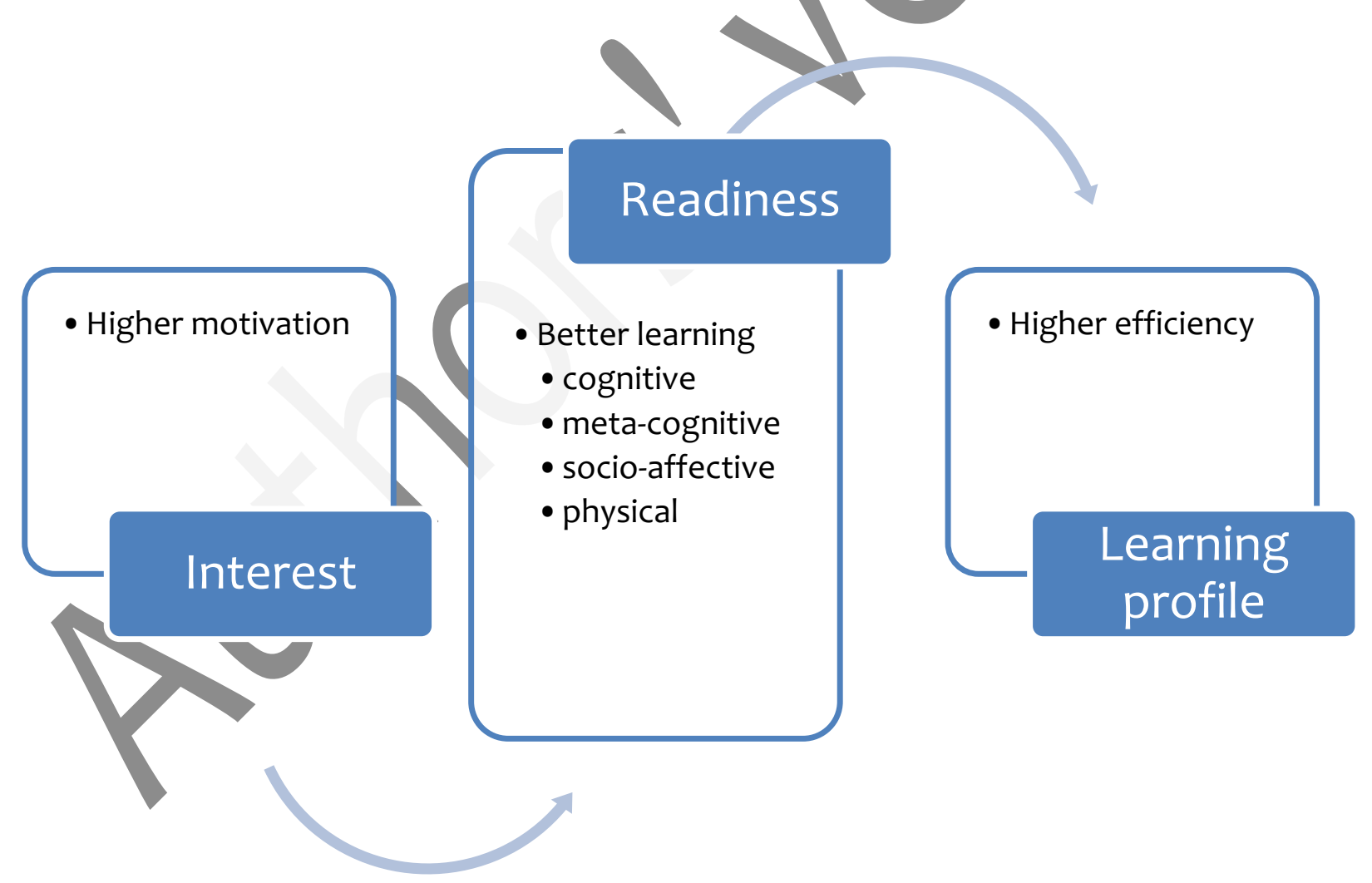

Figure 1: expected learning gains of differentiated instruction (based on Tomlinson, 2017)

Interestingly, working with the differences of interests, readiness and learning profile offers a non-stereotypical, non-discriminating and non-judgmental way of approaching differences which impact learning. Knowing that interests, readiness and learning profiles are conceptualized as 
dynamic students' academic differences, differentiated instruction offers a flexible pedagogicaldidactical concept that avoids labelling and stigmatizing students. As such, differentiated instruction is essentially different from a target-group-specific teaching approach, such as approaches for gifted students, students with disabilities, students with other mother tongues. Yet, differentiated instruction has a great deal in common with these approaches, as the learning needs of these target-groups will reveal themselves through the three differences in learning (interests, readiness and profile).

\section{Philosophy and practices of Differentiated Instruction: the DI-Quest model}

Adapting teaching to the three differences in learning (interests, readiness and profile) is possible through a wide variety of practices, ranging from everyday responsive teacher-student interactions to invasive teaching methods that require substantial planning, sophisticated classroom organization and thoughtful classroom management (e.g. working with learning centers, tiered instruction, dynamic assessments), highlighting the carefully planned, positive and proactive nature of differentiated instruction (Tomlinson, 2017).

However, Tomlinson (2017) states that differentiation is not a recipe for teaching. It requires both a philosophy and an approach to teaching. In fact, the way a teacher looks at learning and teaching has an impact on the successful implementation of differentiated instruction (Tomlinson, 2017), underlining the importance of the teachers' mindset. Comparing teachers' philosophy and practices across contexts requires a measurement tool that can be administered easily, integrating the key ideas and concepts that are used in academic and professional literature on differentiated instruction (DI). The DI-Quest model and instrument have been developed for that aim (Coubergs et al., 2017). Figure 2 presents the DI-Quest model.

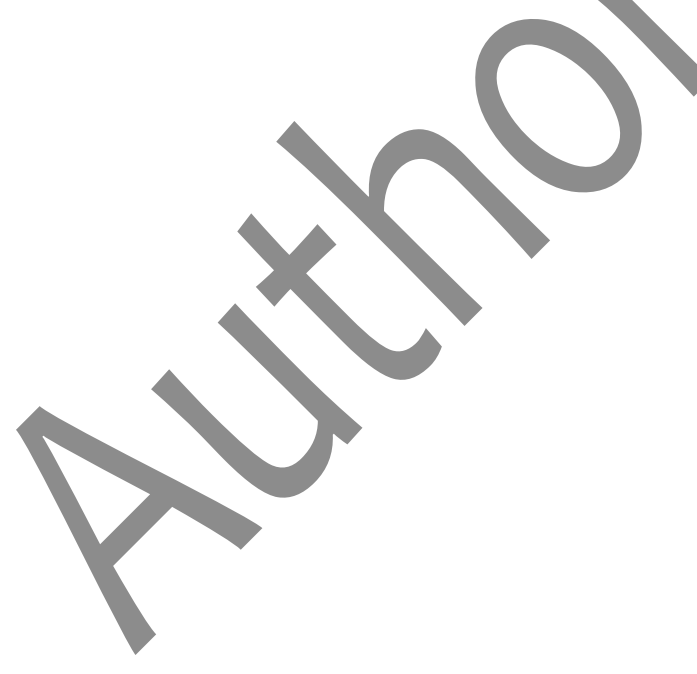




\section{DI-Quest model: Differentiated instruction}

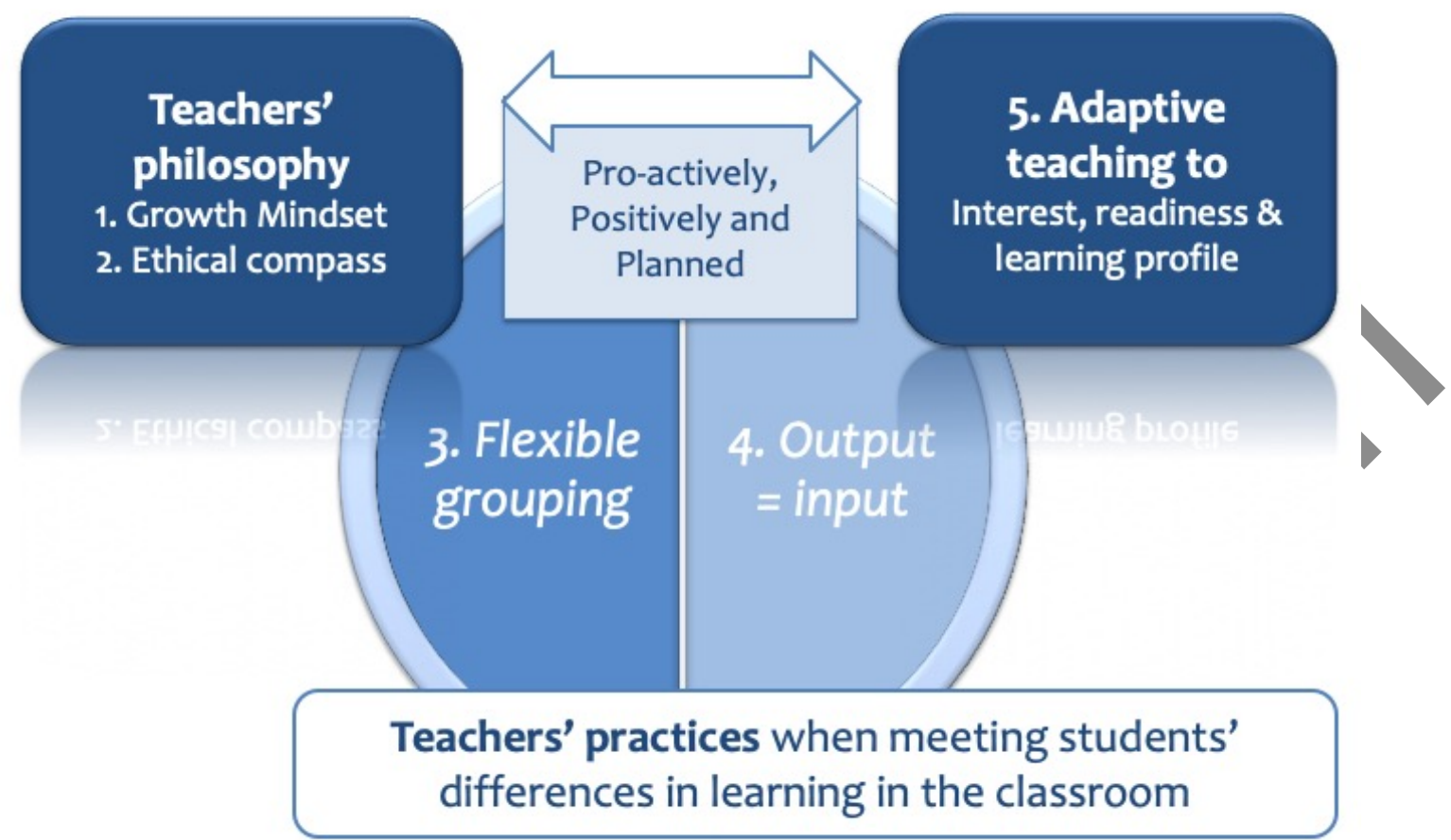

Figure 2: the DI-Quest Model (based on Coubergs et al., 2017)

Five factors describe the current state of affairs with regard to differentiated instruction from the teachers' perspective, including the philosophy and practices of teaching. The DI-Quest model encapsulates two factors related to the teachers' philosophy (i.e. (1.) growth mindset and (2.) ethical compass) and two associated with teaching practices (i.e. (3.) flexible grouping and (4.) output=input), which inform the last factor of (5.) adapting teaching to students' interests, readiness and learning profile (see Figure 2 ).

Factor 1: Growth mindset

Dweck (2006) distinguishes two types of mindsets, namely the fixed and the growth mindset. In a fixed mindset, the teachers tend to believe that the students' qualities, like their talent or intelligence, are fixed traits determining their success, without taking effort into account. Typical presumptions are: 'Some students have what it takes, others do not'. In contrast, teachers with a growth mindset believe that most learning can be achieved through dedication and hard work. In this perspective, every student can be successful if they put in effort. The DI-Quest model demonstrates that a fixed mindset negatively predicts the adaptive teaching related to students' interests, readiness and learning profile. In contrast, the theoretically opposite 'growth mindset' is empirically a positive predictor of differentiated instruction. 
The second factor, the so-called 'ethical compass' describes teachers' perceptions of the use of different curricula as a compass for learning versus the observation of the student as a compass for learning. On the professional compass of the teacher who adapts teaching to students' interests, readiness and learning profiles, the observation of students' learning indicates the magnetic north. The other directions relating to meeting curriculum requirements (such as following textbooks, addressing all standards, expectations of the school leader, management or inspection) are orienting and should be adopted as means to meaningful learning for all students. The DI-Quest shows that strictly following a curriculum, without taking students' needs into account, negatively predicts the use of differentiated instruction (Coubergs et al., 2017). A perceived focus on student observations of learning demonstrates the contrary.

Factor 3: Flexible grouping strategies

The third factor, flexible grouping, is referred to as the variation in grouping forms, such as cooperation in homogeneous and heterogeneous groups (Tomlinson, 2017) and includes forms such as independent work or working in pairs. The criteria of variation in grouping form are associated with the academic differences in students' interests, readiness and learning profile. For example, if the teacher notices considerable differences between struggling students and advanced students, the teacher may decide to adopt tiered instruction in order to guarantee learning gains for all students. Switching flexibly between homogeneous and heterogeneous groups can help students to progress based on their abilities (when in homogeneous groups) and facilitate learning from interaction (when in heterogeneous groups), while also having opportunities to learn independently and encouraging positive group dynamics in the social entity of a class group.

Please note that a 'homogenous group' is a myth. Although students might be grouped in homogenous groups based on one criterion or academic difference (e.g. readiness), the groups will be - almost unavoidably - heterogenous for the other two academic differences (e.g. interests and learning profile).

Factor 4: Output=input

Tomlinson (2001) states that in the classroom where DI is central, the teacher does not perceive the evaluation as the endpoint of a learning process, but rather as a continuous monitoring of why, what and how the students learn. For example, questions which arise are: Do they understand the assignment? Do (some) students experience difficulties? What help do students ask for? What is interesting to (some) students? How do the students think about this assignment? Do they like this approach? Who does (not)? Output=input underlines the importance of continuously adopting the 'output' of students as a piece of information about student learning. This information can be used as 'input' for the students in terms of learning. Likewise, this information is important for the teacher in order to adjust instruction and teaching according to the 'why, what and how' needs of learning of students. The DI-Quest shows that including feedback as an essential part of learning positively predicts the use of differentiated instruction. 
Factor 5: Adaptive teaching to student interests, readiness and learning profiles

All four factors mentioned above contribute to the fundamental goal of DI (factor 5), which consists of adapting teaching to students' interests, readiness and learning profile for maximal learning to occur (see examples described above). The DI-Quest model reveals that adaptive teaching is predicted by teachers' philosophies (i.e. growth mindset and ethical compass) and their practices (i.e. flexible grouping and output=input) (Coubergs et al. 2017). Differentiated instruction occurs ideally when teachers have all these factors in mind.

\section{Teaching student teachers to adopt differentiated instruction}

The DI-Quest model describes five discriminating factors which represent teachers' differentiated instruction philosophy and daily classroom practices resulting in adapting teaching to students' interests, readiness and learning profiles. In what ways can the model be useful for student teachers to learn to adopt differentiated instruction?

What and how of DI, but never without the Why

Recent research, adopting the DI-Quest instrument, shows that there are three profiles of teachers: (1) the DI-teacher with typically high scores on each of the five factors, and two groups of teachers who adapt their teaching to interests, readiness and learning profiles to a lesser extent, namely (2) the fixed mindset group and the (3) formal teachers' group (Gheyssens et al., n.d.). Intriguingly, the latter groups show remarkably low scores on one philosophy-related factor, namely they score low on the 'growth mindset' (for the fixed mindset group) or low on the 'ethical compass' (for the formal teachers' group, in which perceptions of the formal curriculum is steering their teaching, allowing little opportunity to adapt teaching to students' needs).

Transferring these insights to a teacher education context, it is hypothesized that student teachers can learn about what DI is and how they can apply this. However, in order to impact student teachers' adoption of differentiated instruction the why-question needs to be addressed as it relates to teachers' philosophy of learning and teaching. In fact, the teacher has a considerable impact on student learning (e.g. Hattie, 2012).

In the fixed mindset group, intelligence is perceived to be entirely determined by biological, genetic and socio-economic factors. The teacher cannot do anything to change this. Alternatively, if 'every student can learn' and 'if student effort is needed to be successful', the teacher's job is to find a way to trigger students into making an effort. Adapting teaching to students' interests, readiness and profile, which can stimulate students to invest an effort, is what DI-teachers are looking for.

Likewise, the beliefs of the group of formal teachers inhibit the adoption of more frequent DIapproaches. Teachers who are preoccupied with teaching the formal curriculum in a one-size-fitsall approach in order to get approval of parents, school management or inspection may unintentionally - neglect students' learning needs in the everyday hassle to get work done. In fact, when the teachers' focus is on teaching, they like to make sure that all contents and goals 
are covered, that all exercises and chapters in the course materials are tackled, that remedial exercises and self-tests are available and that everything is carefully assessed. What may be forgotten is that a focus on teaching is different from a focus on learning. Making sure that everything is taught is essentially different from making sure that everybody is learning. This latter focus is more apparent with teachers who adopt DI more frequently. Teachers with an ethical compass oriented towards student learning may notice more easily when students cannot follow, when they are struggling or getting distracted, when students are bored or experiencing the learning activities as too easy and adjust their teaching accordingly, looking for renewed student effort (cf. growth mindset). In order to adapt teaching to students' interests, readiness and learning profiles resulting in heightened learning gains (higher motivation, better learning, more efficiently), teachers with an ethical focus on student learning work more actively with the information they observe in class when students are learning (cf. output=input).

In summary, it is important that teacher educators focus on developing both the philosophy and practice of DI among pre-service teachers. Helping, stimulating and challenging student teachers to develop a growth mindset and a focus on student learning guarantees more frequent and conscious investments in differentiated instruction in their classrooms. Ideally, this is being encouraged in courses of the teacher education program, as well as during and following field experiences in schools.

Moreover, teacher educators and mentors need to be aware of their own position as 'role models' for their student teachers. Demonstrating a growth mindset and focus on student learning to student teachers in teacher education, while adopting practices of flexible grouping and output=input will result in more frequent student teachers' experiences of adaptive teaching in their courses and a more explicit DI rationale and pedagogy throughout teacher training. As a consequence, student teachers will be more likely to adopt DI in their classroom practice. Therefore, a persistent and consequent 'teach as you preach' methodology of differentiated instruction in teacher education courses is likely to be more effective for student teachers to adopt differentiated instruction compared to a 'Do as I say, not as I do' method.

\section{Acknowledgement}

A special thanks goes to my Colleagues Catherine Coubergs, Gert Vanthournout and Nadine Engels, who were directly or indirectly involved in the development of the DI-Quest model and the research projects that followed. 


\section{References}

Coubergs C., Struyven K., Vanthournout G., \& Engels N. (2017). Measuring teachers' perceptions about differentiated instruction: the DI-Quest instrument and model. Studies in Educational Evaluation 53, 41-54.

Dweck, C.S. (2006). Mindset: The new psychology of success. New York: Random House.

Gheyssens, E., Coubergs, C., Griful-Freixenet, J., Engels, N., \& Struyven, K. (n.d.). Differentiated instruction: the diversity of teachers' philosophy and practice to adapt teaching to students' interests, readiness and learning profiles. Under review, (minor) revisions needed.

Hattie, J. (2012). Visible learning for teachers: Maximizing impact on learning. New York, USA: Routledge.

Tomlinson C.A. (2017). How to Differentiate Instruction in Academically Diverse Classrooms. Association for Supervision and Curriculum Development, Alexandria, VA. 